\title{
Growth Strains and Stress Relaxation in Alumina Scales during High Temperature Oxidation
}

\author{
P. Y. Hou ${ }^{1}$, A. P. Paulikas ${ }^{2}$ and B. W. Veal ${ }^{2}$ \\ ${ }^{1}$ Lawrence Berkeley National Laboratory \\ 1 Cyclotron Rd. MS: 62-203, Berkeley, CA 94530 \\ ${ }^{2}$ Argonne National Laboratory \\ 9700 S. Cass Ave., Argonne, IL, 60439
}

Keywords: oxidation, $\mathrm{Al}_{2} \mathrm{O}_{3}, \mathrm{FeCrAl}, \mathrm{FeAl}, \mathrm{NiAl}$, reactive element, growth stress, X-ray, Synchrotron radiation, Debye-Sherrer diffraction

\begin{abstract}
A novel X-ray technique was used, exploiting synchrotron radiation at the Advanced Photon Source at Argonne National Laboratory, to investigate the growth stresses in $\alpha-\mathrm{Al}_{2} \mathrm{O}_{3}$. In-situ measurements of Debye-Scherrer diffraction patterns from the scale were recorded during oxidation and cooling, and the elliptical distortion of the diffraction rings was analyzed to yield the in-plane strain. Fe28Al, Fe-40Al, Fe-40Al-0.2Hf, Fe-20Cr-10Al and Ni-50Al (at. \%) were studied. Data were acquired in air at temperatures between $950-1100^{\circ} \mathrm{C}$ and during cool down. In all cases, the steady stage growth strain was relatively low $(<0.1 \%)$ and was either tensile or compressive depending on the alloy. A higher tensile strain often existed during the initial oxidation period when transition alumina was present. Thermal stresses imposed on $\mathrm{NiAl}$ by reducing the sample temperature to $950^{\circ} \mathrm{C}$ for a period of time showed noticeable stress relaxation by creep. Different degrees of relaxation were also found during cooling depending on alloy composition and scale microstructure. On all Fe-based alloys, the first formed $\alpha$ $\mathrm{Al}_{2} \mathrm{O}_{3}$ was highly textured with the degree of texture decreasing with further oxidation. The relationships between stress development, scale wrinkling, oxide phase changes, and the effect of reactive element addition on growth stresses are discussed. Results are compared with other reports of growth stresses in $\mathrm{Al}_{2} \mathrm{O}_{3}$ scales.
\end{abstract}

Introduction. The existence of oxide growth stresses has been known for decades [1]. At high temperatures, the oxidizing components often respond to the stress by plastic deformation of the substrate, especially if it is thin and weak [2], and/or by deformation of the fine grained oxide [3]. Unrelieved growth stresses can combine with thermal stresses that develop during cooling to initiate and drive scale failure. Although the level of residual growth stress may be just a fraction of the cooling stress, knowing its magnitude is still important for accurate mechanistic modeling of scale or coating failure, which is critical to many industrial applications. Moreover, the magnitude of the growth stress and the mechanism by which the oxidizing component relieves it can affect the microstructure which, in turn, influences scale adhesion. Alternatively, it can be argued that the microstructure, especially that in the scale, can affect the build up and relaxation of the growth stresses [4]. None of these relationships is fully understood. Neither do we know if or how growth stresses vary with alloy composition.

Few studies have followed the development of growth stresses during oxidation, mainly due to experimental difficulties. The task is especially challenging for $\mathrm{Al}_{2} \mathrm{O}_{3}$ forming alloys, due to their high temperatures of oxidation, and the slow growth rates and weak x-ray scattering of the $\mathrm{Al}_{2} \mathrm{O}_{3}$ scales. Several attempts have been made, at oxidation temperatures between $950-1200^{\circ} \mathrm{C}$, to determine the stress level using deflection techniques [5-8] and x-ray diffraction [9-11]. Residual stresses measured at room temperature have also been used to extract information about the growth stress. In this procedure, it is assumed that no stress relaxation occurs during cooling and that the stresses resulting from thermal 
expansion mismatch between the scale and the alloy are accurately known. Alloy dimensional changes have been used to qualitatively indicate the state of the growth stress [12,13]. Quantitative measurements of growth stresses were obtained by coupling measured dimensional changes with residual stress measurements [14].

To date, reported stress results from $\alpha-\mathrm{Al}_{2} \mathrm{O}_{3}$ formed on $\beta-\mathrm{NiAl}$ are in better agreement than those found on Fe-based alloys. All studies on $\mathrm{NiAl}$ showed initial tensile stresses related to the phase transformation from transition alumina to alpha. After this transformation is complete, the stress is near zero [10,15] or slightly compressive (-80 MPa) [11], except a recent in-situ XRD study done at $950^{\circ} \mathrm{C}$, which found 500 MPa tensile stress [8]. The effect of a reactive element, Hf, was to reduce the small compressive growth stress to zero [11], or raise the tensile stress from 500 to $600 \mathrm{MPa}$ [8].

Although more data exist for FeCrAl alloys, the agreement between the reported studies is poor. All deflection results showed initially high compressive growth stresses (from -250 to -900 MPa) [5-7], and levels deduced from room temperature residual stress measurements ranged from $(-0.3$ to $-1.8 \mathrm{GPa})$ $[9,15,16]$. A study of room temperature stress levels coupled with specimen length change found high tensile $(1.2 \mathrm{GPa})$ or low compressive $(-0.1 \mathrm{GPa})$ growth stresses during the initial stage of oxidation $(0.1$ hr) at $1000^{\circ} \mathrm{C}$, but the stresses were all compressive (up to $-1.2 \mathrm{GPa}$ ) after longer times at $1000^{\circ} \mathrm{C}$ and at all times at higher temperatures. After oxidation at $1100-1300^{\circ} \mathrm{C}$ followed by cooling to room temperature, specimens usually extended $[13,14]$. This result has always been taken as a clear indication of tensile stresses in the alloy and compressive growth stresses in the scale. However, specimen shrinkage has also been reported $[13,12]$, which could be due to extensive spallation or could imply tensile stresses in the oxide. Recent in-situ XRD studies reported growth stresses that are either compressive ( -1 to -1.7 $\mathrm{GPa}$ ) [17] or tensile (20-500 $\mathrm{MPa}$ ) [11], both showing lower absolute levels at higher oxidation temperatures. These stress levels vary a great deal even though the same type of FeCrAlY alloy was used. Clearly, additional studies are needed to resolve this disagreement. Furthermore, the effect of reactive elements on growth stresses is not yet clear. To illustrate, one study using the deflection technique [5] and two that measure specimen dimensional changes $[12,13]$ indicated lower growth stresses with the reactive element, while in-situ XRD measurements showed the opposite [17].

In this work, a novel X-ray technique is used that records Debye-Scherrer diffraction patterns from the oxidizing specimen during oxidation and cooling. Elliptical distortion of the diffraction rings is analyzed to yield the in-plane strain. The goal is to utilize a different in-situ XRD method to try to resolve some of the controversial results on growth stresses that have been reported. This paper reports our first results on several Fe-based alloys with and without $\mathrm{Hf}$ addition and on a single crystal $\beta$-NiAl.

Experimental Method. In-situ strain measurements were performed using x-ray diffraction (XRD) exploiting synchrotron radiation at beamline 12BM at the Advanced Photon Source at Argonne National Laboratory. A schematic of the experimental setup is shown in Fig. 1. The test specimen is placed on a $0.6 \mathrm{~mm}$ thick alumina shelf mounted in a horizontal tube furnace. A thermocouple is located immediately below the sample shelf. The temperature was calibrated by melting a gold foil in the sample position. The $\mathrm{X}$-ray beam, with $21.6 \mathrm{keV}$ energy, strikes the sample at an incidence angle of 2 to $5^{\circ}$. The beam is focused and/or shuttered to a spot size of about $0.2 \mathrm{~mm}(\mathrm{FWHM}) \times 1 \mathrm{~mm}$. Sample dimensions can be quite variable with this setup. In these studies, the polished surface ( $1 \mu \mathrm{m}$ diamond grit) is rectangular, $10 \times 15 \mathrm{~mm}^{2}$, or circular, $\sim 15 \mathrm{~mm}$ dia.; the sample thickness is typically a few $\mathrm{mm}$. The sample is carefully positioned to intercept the entire beam, with no significant over- or under-shoot. Half circles of Debye-Sherrer diffraction rings from the sample are recorded using an image plate detector; an example is given in Fig. 2b. For precise determination of the x-ray scattering center, or any detector misorientation, a porous, sintered alumina is used as a reference. The reference is placed into the x-ray path (Fig. 1b), using 
a pneumatic actuator, after the test specimen is lowered. The x-rays penetrate through this thin reference and yield full-circle diffraction spectra that can be analyzed to obtain the location of the beam centroid to within $\pm 2 \mu \mathrm{m}$. The reference and sample motions are computer driven; typically, a reference spectrum is recorded after five successive sample measurements, each of 5 minutes duration.
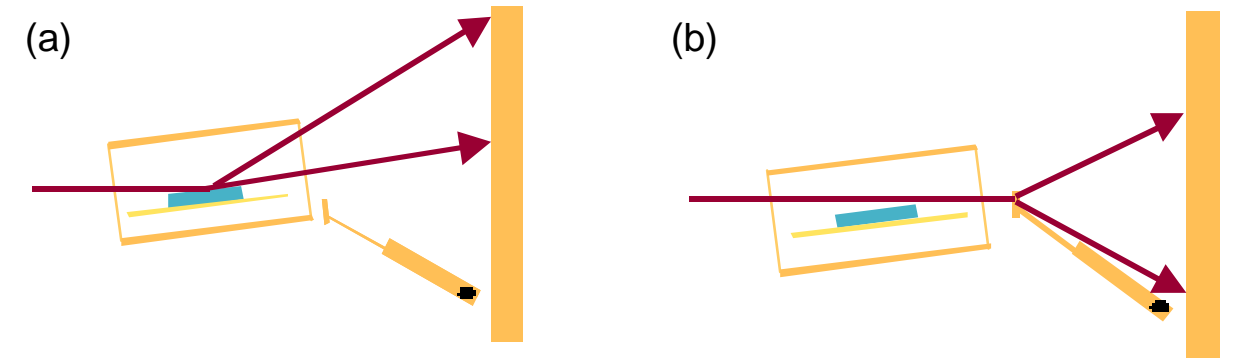

Fig. 1. (a) X-rays strike the sample and generate a Debye-Scherrer diffraction pattern in the upper half plane of the large area detector. (b) To measure the beam position, the sample is lowered and a reference is exposed.
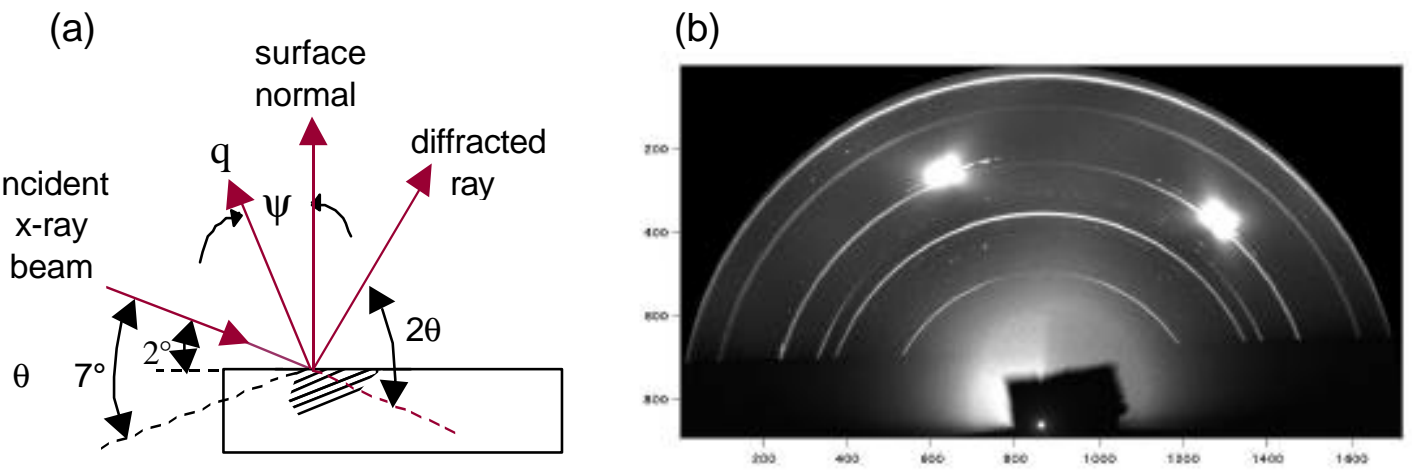

Fig. 2. (a) Schematic of the diffraction arrangement and (b) Diffraction patterns from an $\mathrm{Al}_{2} \mathrm{O}_{3}$ film grown on Fe-40Al-Hf at $1000^{\circ} \mathrm{C}$ for $15 \mathrm{hrs}$. Varying intensity along the rings indicates texture in the oxide, and bright diffraction spots are from the substrate.

The technique is a single exposure method, where diffraction rings from all diffracting planes in the accessible range of $\psi\left(\sim 7-75^{\circ}\right)$ are simultaneously acquired. As shown in Fig. $2 \mathrm{a}, \psi$ is the angle between the sample normal and the scattering vector. Since in-plane and out-of-plane d-spacings of diffracting planes in a stressed film are different, the resulting Debye-Scherrer rings are elliptically distorted. This ellipticity is measured and analyzed, exploiting the entire available diffraction pattern in the upper half plane to determine the strain in the film. With conventional tilting methods, measurements are typically acquired at only a few $\psi$ angles in the Debye-Scherrer pattern. The ability to obtain data from a wide range of $\psi$ angles in the current method not only provides high precision $\left(\sim 2 \times 10^{-5}\right.$ in strain), but also indicates texture, if it exists, and shows the location of any diffraction rings or peaks from substrate grains. Tails from substrate diffraction lines could overlap the oxide diffraction rings altering their shape and give an erroneous ellipticity (strain). The diffraction pattern also shows those oxide phases that may be present at different oxidation times.

Diffracted intensity from the strained lattice planes must satisfy the condition $\sin \theta=\lambda /\left(2 \mathrm{~d}_{\psi}\right)$. Note that, for a diffraction ring from an unstrained oxide, $\theta$ is constant for all $\psi$; the variation in $\theta$ comes from changes in the angle dependent $\mathrm{d}$-spacings caused by strain. The intensity is given by $\mathrm{I}=\mathrm{I}_{\mathrm{bkg}}+\mathrm{C} \times \mathrm{f} \times \exp (2 \theta-$ $\left.2 \theta_{0}\right)^{2} / 2 \mathrm{w}^{2}$ where $\mathrm{I}_{\mathrm{bkg}}$ is a background term, $\theta_{\mathrm{o}}(\psi)=\sin ^{-1}\left[\lambda /\left(2 \mathrm{~d}_{\psi}\right)\right]$ is the centroid of this intensity plot, $\mathrm{w}$ is its Gaussian width and $C$ is the amplitude. It can be shown that $d_{\psi}=d_{0}\left[1+A \sin ^{2} \psi+B\right]$ where $A$ and $B$ are functions of elastic compliance parameters $[18,19]$. It is assumed that the oxide film is isotropic with no 
shear and is under a biaxial stress. The in-plane strain is then given by $\varepsilon_{\text {in }}=[\mathrm{A}(1-\mathrm{v})] /[2 \mathrm{vA}+$ $(1+v)(1+B)]$ where $v$ is the Poisson's ratio. The terms $\mathrm{A}$ and $\mathrm{B}$, as well as $\mathrm{C}$ and $\mathrm{w}$, are treated as fitting parameters in a 3-D plot of the entire (116) intensity of the $\alpha-\mathrm{Al}_{2} \mathrm{O}_{3}$ phase as a function of $\psi$. The function $\mathrm{f}$ is formulated to include effects of absorption, $\mathrm{x}$-ray beam polarization and sample texture.

Test specimens were heated at a linear rate of $1000^{\circ} \mathrm{C} / \mathrm{hr}$ in ambient air. Diffraction patterns were recorded after the sample reached its desired oxidation temperature at $5 \mathrm{~min}$ intervals during the isothermal stage and continuing through cool down. Some iron aluminides were cooled at $300^{\circ} \mathrm{C} / \mathrm{hr}$, otherwise samples were furnace cooled, reaching near ambient temperature in about $1 \mathrm{hr}$. Occasionally, the temperature was reduced and held at a slightly lower level to examine the build up and relaxation of thermal stresses. A single crystal $\beta$-Ni50Al, and five different $\mathrm{Fe}$-based $\mathrm{Al}_{2} \mathrm{O}_{3}$ forming alloys were studied; they are $\mathrm{Fe}-28 \mathrm{Al}, \mathrm{Fe}-40 \mathrm{Al}, \mathrm{Fe}-40 \mathrm{Al}-0.2 \mathrm{Hf}$ and $\mathrm{Fe}-20 \mathrm{Cr}-10 \mathrm{Al}$ (at. \%). Most specimens were oxidized at $1000^{\circ} \mathrm{C}$, and a few at $1100^{\circ} \mathrm{C}$. After the strain study, test samples were examined using scanning electron microscopy. Duplicate specimens oxidized under the same conditions elsewhere were used to reveal the morphological development of the oxide scales.

Results and Discussion. Growth and cooling strains and their relationship with scale development for each alloy are presented and discussed in separate sub-headings here. More general discussions of growth stresses will be presented in the next section.

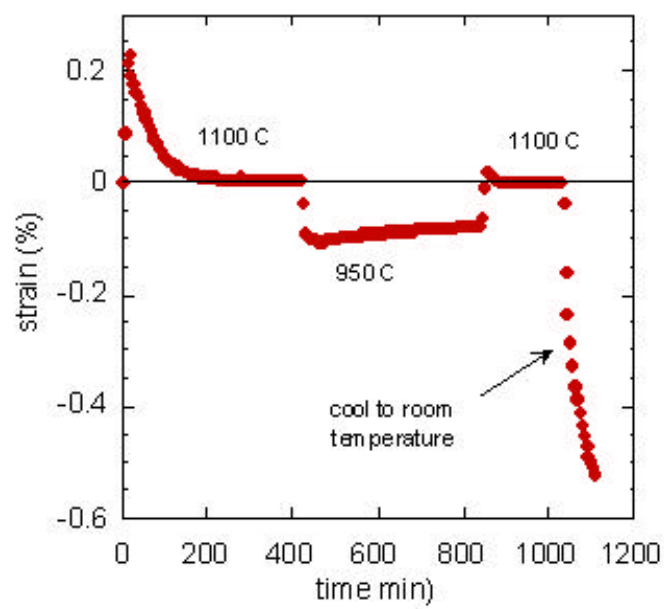

Fig. 3. In-plane strain in $\alpha-\mathrm{Al}_{2} \mathrm{O}_{3}$ grown on $\beta$-NiAl as a function of oxidation time at $1100^{\circ} \mathrm{C}$. Between 400 and $800 \mathrm{~min}$, temperature was reduced to $950^{\circ} \mathrm{C}$ and creep is monitored.

$\boldsymbol{\beta}$-NiAl. Fig. 3 shows the in-plane strain levels in the $\alpha-\mathrm{Al}_{2} \mathrm{O}_{3}$ scale grown on a $2.5 \mathrm{~mm}$ thick single crystal $\mathrm{NiAl}(100)$ sample that was oxidized at $1100^{\circ} \mathrm{C}$. An initial tensile stress $\left(\sim 700 \mathrm{MPa}\right.$, using $\mathrm{E}_{\mathrm{Al} 2 \mathrm{O} 3}=$ $350 \mathrm{GPa}$, where $\mathrm{E}$ is the Young's modulus) was observed which rapidly declined to zero. This behavior is in agreement with previously reported results [8,11]. The initial tensile stress is attributed to the transformation of the first-formed alumina to the more stable alpha form, since this process involves a volume reduction [20]. After the phase transformation was complete, the stress became near zero. Others have also shown the same low steady state growth stress level in NiAl [10,11]. After 400 minutes of oxidation, the temperature was lowered to $950^{\circ} \mathrm{C}$, where it was held for $450 \mathrm{~min}$. The reduced temperature imposed a compressive stress on the oxide as a result of the thermal expansion difference between the oxide and the substrate, and a creep response was observed providing strain relief. Since the oxide/alloy ratio at this time was less than $2 / 2500$, the level of stress in the metal would be no more than 0.6 MPa. The stress relaxation observed here must be due to creep of the fine-grained oxide. After the temperature was returned to $1100^{\circ} \mathrm{C}$, the stain became slightly tensile, but then quickly dropped back to the zero level that was observed before the cooling stage.

Fe-40Al. Fig. 4a shows the in-plane strain levels from $\alpha-\mathrm{Al}_{2} \mathrm{O}_{3}$ scales grown on four different Febased alloys at $1000^{\circ} \mathrm{C}$; each specimen is about $1 \mathrm{~mm}$ thick. The $\mathrm{Fe} 40 \mathrm{Al}$ alloy quickly developed a 
tensile stress of about $600 \mathrm{MPa}$, about the same magnitude as that found on the $\mathrm{NiAl}$, and then it declined to a steady state compressive level of about $-175 \mathrm{MPa}$. A complete layer of $\alpha-\mathrm{Al}_{2} \mathrm{O}_{3}$ forms at the scale/alloy interface on this alloy after $1 \mathrm{hr}$ oxidation at $1000^{\circ} \mathrm{C}$ [21], which is the time in which the measured stress stabilizes to the compressive level. These results again suggest that the initial tensile stress is due to $\mathrm{Al}_{2} \mathrm{O}_{3}$ phase transformation.

During cooling (Fig. 4b) the compressive stress in the $\alpha-\mathrm{Al}_{2} \mathrm{O}_{3}$ increased as a result of the build up of thermal stresses, until scale failure took place at about $400^{\circ} \mathrm{C}$. Observation of the specimen surface after oxidation (Fig. 5a) indicated that the oxide layer was flat and there was extensive spallation, a process that relieved most of the growth and thermal stresses that had built up in the scale.
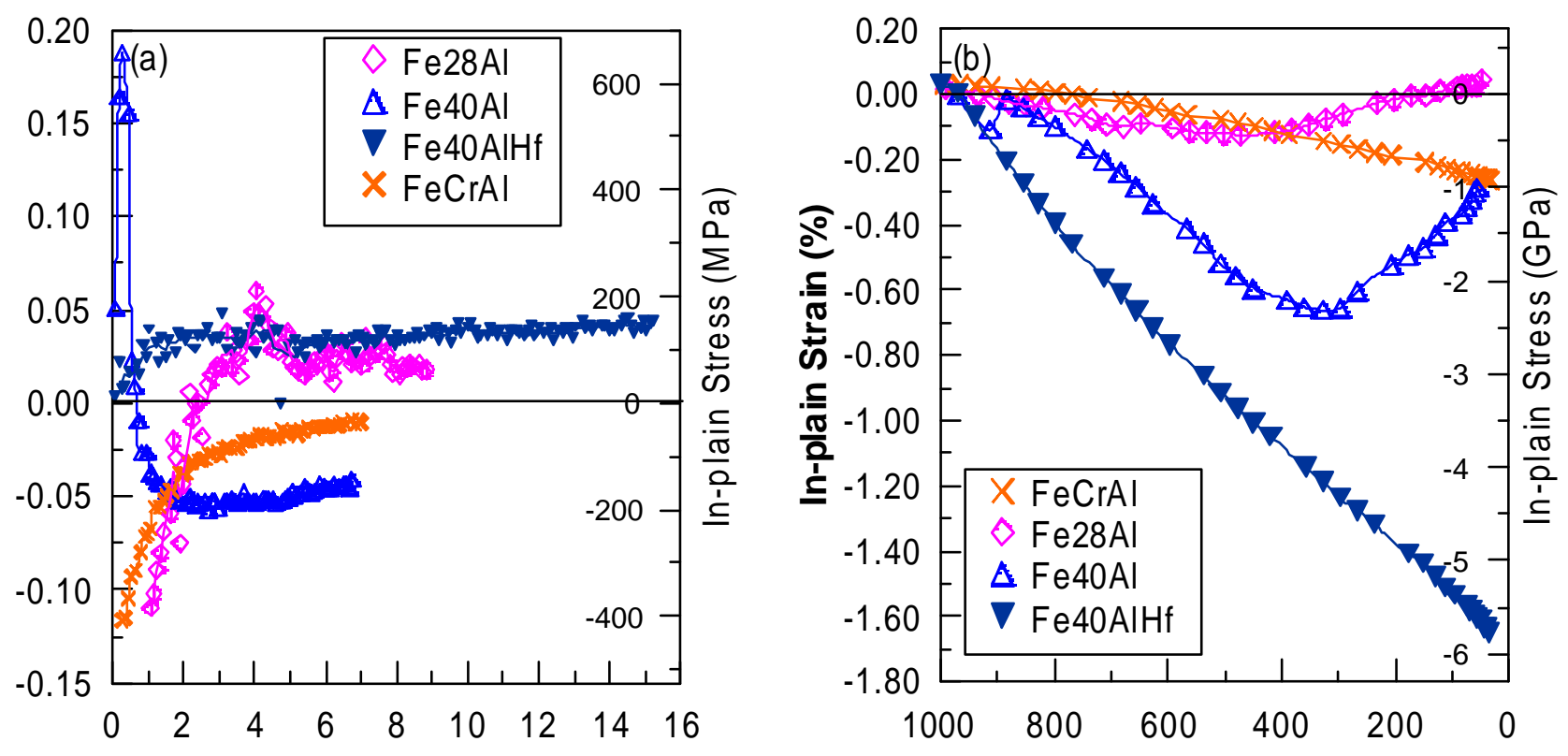

Fig. 4: Strains in $\alpha-\mathrm{Al}_{2} \mathrm{O}_{3}$ grown on different Fe-based alloys during oxidation at $1000^{\circ} \mathrm{C}$ (a) and during cooling (b).

Fe-28Al. The diffraction patterns from this alloy in the initial stages were complex, showing transition alumina and other phases, probably iron oxides or $\mathrm{Fe}, \mathrm{Al}$ spinel; steady strain levels with time were only obtained after the first hour. At this time, the $\mathrm{Al}_{2} \mathrm{O}_{3}$ phase transformation should have been completed, since a complete $\alpha-\mathrm{Al}_{2} \mathrm{O}_{3}$ layer on this alloy develops after $\sim 15$ minutes at $1000^{\circ} \mathrm{C}$ [21]. The stress in the $\alpha-\mathrm{Al}_{2} \mathrm{O}_{3}$ is seen from Fig. $4 \mathrm{a}$ to be compressive at $1 \mathrm{hr}$, about $-350 \mathrm{MPa}$, but slowly relaxed, in the tensile direction, to a steady state tensile level of $\sim 105 \mathrm{MPa}$ after $3.5 \mathrm{hrs}$. Previous studies of this alloy [22] have shown that wrinkling of the scale and the alloy occurs early on, before $2 \mathrm{hrs}$, and the behavior is initially dependent upon alloy grain orientation, i.e., scales on some alloy grains wrinkled, while scales on other grains remained flat. Soon after the wrinkling, some of the scale loses adhesion with the alloy and growth buckles develop; an example of this morphology can be seen in Fig. 5b. The growth stress measurements presented here are consistent with this microstructural evolution. Since the first formed scale is compressively stressed, wrinkling takes place, which relaxes the apparent stress to near zero. Once the surface is wrinkled, there is a stress component in the z-direction and there are shear stresses in the scale, so the assumption of a purely biaxial stress state with no shear is no longer valid. It is not yet resolved if the steady state tensile level detected after extensive wrinkling is due to a breakdown of this assumption, a preferential measurement on the peaks of the wrinkles, or an experimental error of the absolute level of zero stress. Although unstrained bulk alumina has not yet been tested, a piece of loosely sintered $\mathrm{Cr}_{2} \mathrm{O}_{3}$ placed in the sample position confirmed the zero level to within $0.01 \%$ strain. 
Fig. 5b shows the scale morphology after the test specimen was cooled to room temperature. Many areas have extensive scale buckling with little scale to alloy contact. The buckles must have developed at the oxidation temperature because the alloy surface beneath them is often smooth and facetted without any sign of oxide imprints. During cooling, the buckles probably grew to relax some thermal stresses. This is why the build up of cooling stress is much less on this alloy as compared with other FeAl's (Fig. 4b). Additional stress relaxation took place at temperatures below $500^{\circ} \mathrm{C}$, probably due to spallation from the unbuckled areas.
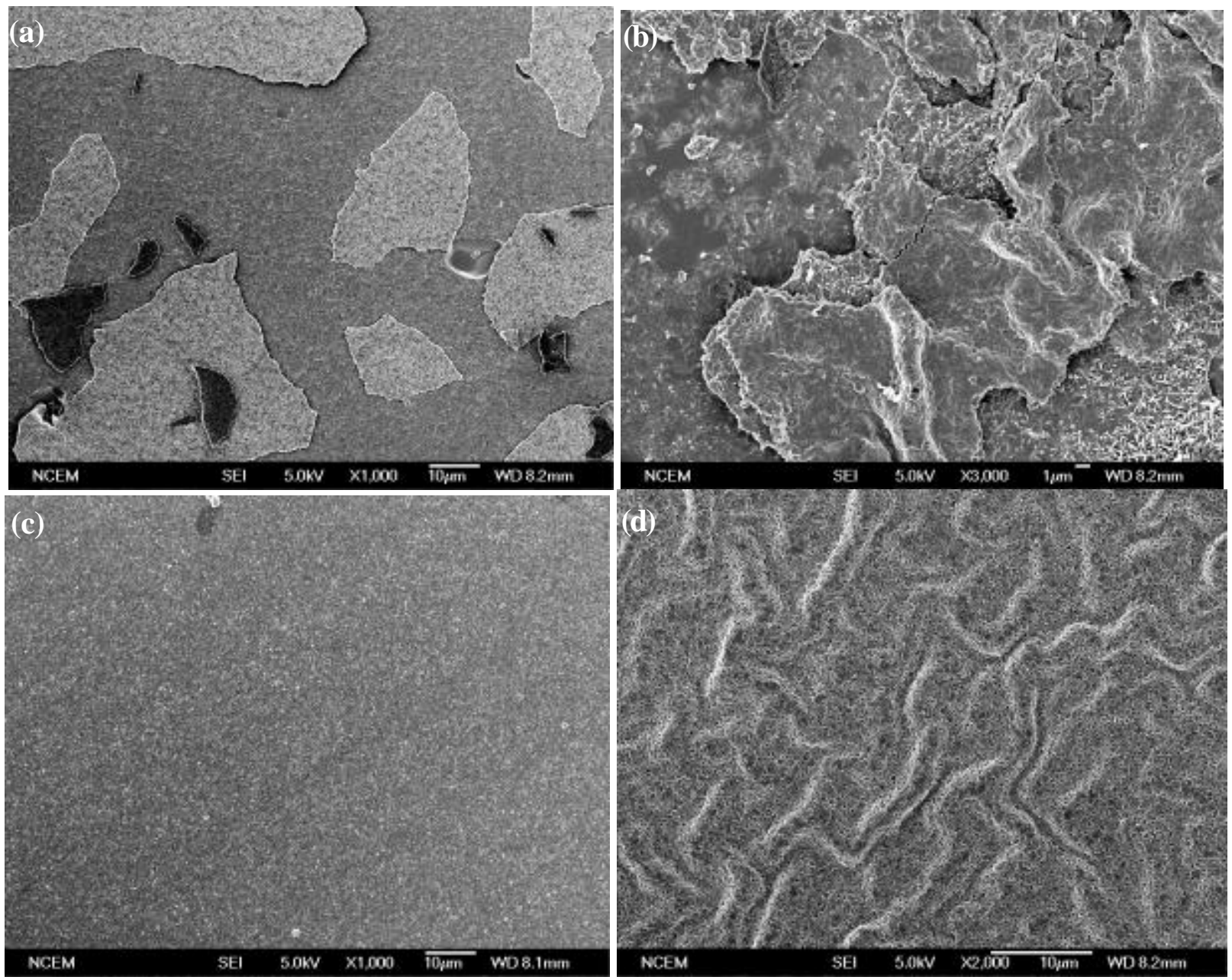

Fig. 5: SEM images of the surfaces of oxidized (a) Fe40Al, (b) Fe28Al, (c) Fe40AlHf and (d) FeCrAl.

Fe-40Al-Hf. When a reactive element was present in Fe-40Al, the scale became very adherent. No sign of failure was observed after oxidation and cooling (Fig. 5c). As a result, the thermal strain continued to increase to a compressive level of $-1.65 \%$ (Fig. 4b), which is expected from calculations based on the thermal expansion mismatch of the alloy and the oxide, at $-1.5 \%$. The growth stress, however, showed a peculiar behavior (Fig. 4a). It was at all times low and tensile, increasing from near zero at the very early stage to close to $175 \mathrm{MPa}$ at the end of the oxidation run. Reactive element additions usually retard the $\alpha$ $\mathrm{Al}_{2} \mathrm{O}_{3}$ transformation [23], so if the initial tensile stress seen on the $\mathrm{Fe}-40 \mathrm{Al}$ is due to this transformation, the same kind of tensile stress should also be detected here and it should last longer, unless the initial growth stress on this alloy is highly compressive such that it overwhelms the transformation stress. Another possibility is that the highly textured initial scales, giving rise to non-uniform intensity distribution of the diffraction rings, caused errors in the strain analysis, making the initial stage strain data not trustworthy. However, texture became less apparent after the first few hours, but the steady state stress level remained 
tensile. Since the scale in this case is flat and adherent, the assumption of a biaxial stress state should be valid. The presence of this low steady state tensile stress is under further investigation.

FeCrAl. Like Fe-28Al, this alloy also develops a wrinkled morphology, and at $1000^{\circ} \mathrm{C}$, wrinkling starts after about 30 minutes. However, scale adhesion is stronger, so there is little separation from the alloy, even during cooling (Fig. 5d). Consequently, thermal stresses build up on cooling without sudden relaxation as on Fe-28 and 40Al (Fig. 4b). The final stress level at room temperature is lower than that found on the $\mathrm{FeAl}$ alloys due to a smaller thermal expansion mismatch between $\mathrm{FeCrAl}$ and $\mathrm{Al}_{2} \mathrm{O}_{3}$ [24]. The calculated thermal strain is $-0.6 \%$, which is higher than the measured final level of $-0.3 \%$. Thus there must be stress relaxation during cooling (the small compressive growth strain contributes very little to the residual strain). Judging from the slope of the cooling curve, most relaxation occurred during the first $350^{\circ} \mathrm{C}$; the wrinkles probably continued to grow to relax some of the thermal stresses.

The first measurement of growth stress in the early stage scale, taken $\sim 0.3 \mathrm{hr}$. after the oxidation temperature was reached, was compressive, about $-408 \mathrm{MPa}$. This early stage stress showed relaxation that was initially almost exponential (up to $\sim 2 \mathrm{hrs}$ ) followed by nearly parabolic behavior, reaching a steady state of less than $-40 \mathrm{MPa}$. This behavior agrees well with current understanding of the oxide development on this alloy. At $1000^{\circ} \mathrm{C}, \alpha-\mathrm{Al}_{2} \mathrm{O}_{3}$ is the major phase on $\mathrm{FeCrAl}$ after 16 minutes [25]. Relaxation of the compressive stress must be achieved by the wrinkling of the scale and the $\mathrm{FeCrAl}$ alloy, which is known to occur during oxidation, and the phenomenon is believed to be driven by the biaxial compressive stress in the oxide film $[26,27]$.

General Discussion. Of the five alloys tested, NiAl, FeCrAl, Fe28Al, Fe40Al and Fe40Al with Hf, steady state residual growth stresses after $2 \mathrm{hrs}$ at $1000^{\circ} \mathrm{C}$ were all very low, ranging from -175 to 140 $\mathrm{MPa}$. Stress relaxation studies carried out on $\mathrm{NiAl}$ at $950^{\circ} \mathrm{C}$, following oxidation at $1100^{\circ} \mathrm{C}$, showed faster stress relief by oxide creep than stress build up by oxidation. These results suggest that residual growth stresses in fine grained alumina scales (usually between 100-200 nm 28]) formed at oxidation temperatures as high as $1000-1100^{\circ} \mathrm{C}$, are not at the GPa levels shown by other studies [9,17]. Such high stress levels are particularly unlikely on FeCrAl where extensive scale and alloy wrinkling takes place as a plastic response to the growth stress. Furthermore, we can infer from the cooling data of Fig $4 \mathrm{~b}$ that this kind of wrinkling morphology is able to relax, within $1 \mathrm{hr}$, most of the thermal stress that would have built up on cooling from 1000 to $800^{\circ} \mathrm{C}$. The effectiveness of stress relaxation during cooling is obviously a function of cooling rate. Future work will study this effect more extensively.

The determination of growth stresses in early stage scales using x-ray diffraction techniques is complicated by several factors. The first formed $\mathrm{Al}_{2} \mathrm{O}_{3}$ is generally not the $\alpha$-phase but slowly transforms to $\alpha$ at temperatures above $1000^{\circ} \mathrm{C}$. This transformation, with an associated volume change, can give rise to an initial tensile stress. Strong diffraction peaks from grains in the alloy and diffraction rings from other oxide phases can introduce errors into the strain analysis. Furthermore, the first-formed $\alpha-\mathrm{Al}_{2} \mathrm{O}_{3}$ on all tested alloys except $\mathrm{NiAl}$ showed strong texture, giving rise to very nonuniform intensities around the diffraction rings. Incorporation of base metals into the first formed $\mathrm{Al}_{2} \mathrm{O}_{3}$ scale is known, and this kind of compositional change will also complicate strain measurements when a lattice parameter is used as a strain gauge unless careful corrections are made.

Conclusions. In-situ x-ray diffraction measurements, exploiting synchrotron radiation, have been used to measure growth strains in $\alpha-\mathrm{Al}_{2} \mathrm{O}_{3}$ scales thermally grown on the alloys $\mathrm{Fe}-28 \mathrm{Al}, \mathrm{Fe}-40 \mathrm{Al}, \mathrm{Fe}-40 \mathrm{Al}$ $0.2 \mathrm{Hf}, \mathrm{Fe}-20 \mathrm{Cr}-10 \mathrm{Al}$ and $\mathrm{Ni}-50 \mathrm{Al}$ (at. \%). For Ni-50Al, oxidized at $1100{ }^{\circ} \mathrm{C}$, zero growth stress was observed in the oxide after an initial $\sim 700 \mathrm{MPa}$ tensile stress attributed to $\mathrm{Al}_{2} \mathrm{O}_{3}$ phase transformation. After reducing the temperature from 1100 to $950^{\circ} \mathrm{C}$ to impose a compressive stress on the scale (exploiting thermal mismatch between oxide and substrate), stress relaxation, achieved by oxide creep, was 
able to reduce the imposed strain by about $25 \%$ in $7.5 \mathrm{hrs}$ at $950^{\circ} \mathrm{C}$. Fe-40Al retained a residual compressive stress of $\sim 175 \mathrm{MPa}$ after the scale had transformed to $\alpha-\mathrm{Al}_{2} \mathrm{O}_{3}$. Fe-28Al had $\sim 420 \mathrm{MPa}$ of compressive stress after the first hour of oxidation, which quickly relaxed to $\sim 70 \mathrm{MPa}$ after scale wrinkling and buckling. Similar behavior was observed for FeCrAl, as the initial compressive stress in $\alpha$ $\mathrm{Al}_{2} \mathrm{O}_{3}$ was relaxed by scale wrinkling, leaving a steady state level of $\sim-40 \mathrm{MPa}$. The effect of adding $\mathrm{Hf}$ to $\mathrm{Fe} 40 \mathrm{Al}$ was to reduce the compressive growth stress; with Hf, the stress level was slightly tensile at all times. It is yet not clear why the growth stress should be tensile in this case. Work is in progress to investigate more reactive element containing alloys.

Acknowledgment. Research sponsored by the U. S. Department of Energy, BES, Materials Science, under contracts No. DE-AC03-76SF00098 and W-31-109-ENG-38.

\section{References}

[1] See for example the review by J. Stringer, Corr. Sci., Vol. 10 (1970), p.513

[2] H.E. Evans and M.P. Taylor, Surf. Coatings Tech. Vol. 94-95 (1997), p.27

[3] M. Schutze, Mater. Sci. Tech., Vol. 6 (1990), p.32

[4] R.M. Cannon and P.Y. Hou, in "High Temperature Corrosion and Materials Chemistry", ed. P. Y. Hou, M. J. McNallan, R. Oltra, E. J. Opila and D. A. Shores, the Electrochem. Soc., 1998, p.594

[5] D. Delaunary, A.M. Huntz and P. Lacombe, Corr. Sci., Vol. 20 (1980), p.1109

[6] S.R.J. Saunders, H.E. Evans, M. Li, D.D. Gohil and S. Osbergy, Oxid. Metals, Vol. 48 (1997), p.189

[7] Meishuan Li, Tiefan Li, Wei Gao and Zhenyu Liu, Oxid. Metals, Vol. 51 (1999), p.333

[8] N. Eisenreich, H. Fietzek, M.J. Garcia-Vargas, M. Juez-Lorenzo and V. Kolarik, J. Corr. Sci. Eng., Vol. 6 (2003), paper H062.

[9] C. Sarioglu, J. R. Blachere, F. S. Pettit and G. H. Meier, in Microscopy of Oxidation 3, eds. S. B. Newcomb and J. A. Little, The Institute of Materials, London, (1997), p. 41

[10] E. Schumann, C. Sarioglu, J.R. Blachere, F.S. Pettit and G.H. Meier, Oxid. Metals, Vol. 53 (2000), p.259

[11] P.F. Tortorelli, K.L. More, E.D. Specht, B.A. Pint and P. Zschack, Microscopy of Oxidation V, Limerick, Ireland, Aug. 26-28, 2002, to be published in Materials High Temp.

[12] C. Forest and J.H. Davidson, Oxid. Metals, Vol. 43 (1995), p.479

[13] M.C. Stasik, F.S. Pettit, G.H. Meier, A. Ashary and J.L. Smialek, Scripta Meter., Vol. 31 (1994), p.1465

[14] V.K. Tolpygo and D.R. Clarke, Oxid. Metals, Vol. 49 (1998), p.187

[15] D.M. Lipkin and D.R. Clarke, Oxid. Met., Vol. 45 (1996), p.267

[16] R.J. Christensen, V.K. Tolpygo and D.R. Clarke, Acta Meter., Vol. 445 (1997), p.1761

[17] C. Sarioglu, M.J. Stiger, J.R. Blachere, R. Janakiraman, E. Schumann, A. Ashary, F.S. Pettit and G.H. Meier, Mat. and Corr. Vol. 51 (2001), p.358

[18] I.C. Noyen and J.B. Cohen, "Residual stress measurement by diffraction and interpretation", Materials Research and Engineering (Ed. by B. Ilschner and N. J. Grant, Springer-Verlag, New York, Berlin), 1987.

[19] B.W. Veal and A.P. Paulikas, unpublished results.

[20] J. Doychak and M. Ruhler, Oxid. Metals, Vol. 31 (1989), p.431

[21] P.Y. Hou, J. Mater. Sci. Lett., Vol. 19 (2000), p. 577

[22] Z.G. Yang and P.Y. Hou, "Wrinkling behavior of alumina scale formed during isothermal oxidation of FeAl binary alloys", paper submitted to Mater. Sci. Eng. A.

[23] B.A. Pint, Mate. Sci. Forum,Vol. 251-254 (1997), p.397

[24] I.G. Wright, B.A. Pint and P.F. Tortorelli, Oxid. Metals, Vol. 55 (2001), p.333

[25] A. Andoh, S. Taniguchi and T. Shibata, Mater. Sci. Forum, Vol. 369-372 (2001), p.303

[26] J. K. Wright, R. L. Williamson, D. Renusch, B. Veal, M. Grimsditch, P. Y. Hou and R. M. Cannon, Mater. Sci. and Eng., Vol. A262 (1999), p.246

[27] V. K. Tolpygo and D. R. Clarke, Acta mater., Vol. 46 (1998), p.5153

[28] P. Y. Hou, X. F. Zhang and R. M. Cannon, Scripta Meter, Vol. 51 (2004), p.45 